\title{
Development of Personal Injury Claim Mobile Applications using Odgen Table
}

\author{
Nik Ruslawati Bt Nik Mustapa ${ }^{1 *}$, Hussin Bin Abd Hamid ${ }^{2}$ \\ ${ }^{1,2}$ Faculty of Computer \& Mathematic Sciences \\ UniversitiTeknologi MARA, Tapah Campus, Perak Branch , \\ Tapah Road,35400 Perak
}

\author{
Corresponding author: *nrnm@uitm.edu.my \\ Received Date: 27 June 2019 \\ Accepted Date: 16 October 2019
}

\begin{abstract}
Personal injury claim can be found if any accident occurs such as road accident. After the accident occur the victim which is humankind can claim the compensation to himself regarding to injury in that accident. This claim involve law to determine the compensation amount to the victim.Unfortunately, in Malaysia multiplier-multiplicand approach still used by the court. This approach is outdated and unfair to victim as it's not seen through the victim personal condition. So, the personal injury claim applicationwhich is it using Ogden table were implemented to calculate the compensation amount to victim. This Ogden table is special since it's seen through in all aspect of victim personal condition. This application is build using Android Studio and Atom. This application has information about claimant, court and lawyer. It also can calculate the compensation amount more accurately to claimant. The target users of this application are claimant which is the victim, lawyer and court.
\end{abstract}

Keywords: Personal Injury Claim, Odgen Table, mobile application, compensation

\section{INTRODUCTION}

Personal injury claim is a process used to claim the compensation amount for those who has suffered from injury which not caused by themselves. A personal injury can be a physical or psychological injury or illness. A claim occurs when someone has been injured by others mistakes for example road accident. In Malaysia, still practice 
multiplier-multiplicand approach to calculate the claim (Mohamad, Hashim, \& Khalid, 2012). Lately in Malaysia, an accident that is related to the different type of vehicles keep increasing. According to the Malaysian Institute of Road Safety Research (MIROS) as cited by Ali, Saleh, Jamian, Mustapa \& Yahya (2017), MIROS reported that there are 521,466 cases of road traffic accidents recorded in 2016 as compared to 489,606 cases in 2015. As the road accident increase, the rate of the claimant to claim their claim also increase.Massita et al. (2012) and Lim (1995) defined compensation as award of amount given to the wrong party who had pleaded responsible for the offenses committed and requires certain amount of payment to victims or beneficiaries' parties. As to the compensation or damages, all the vehicle owners registered to third party insurance covers special damages and general damages. Special damages mostly cover vehicle and property damages. General damages refer to pain and suffering resulting from injuries to a person.

Currently the approach that used in Malaysia which multipliermultiplicand approach is shown their approach do not corresponding with the current changes and it became incompatible overtime (Mohamad et al., 2012).For example, the government have update the retirement age until 60 years old. Regarding to this approach, the compensation does not considered the personal issues such as status of occupations, ages, gender, educational level, capability before and after accident, working status before and after accident and part on injury (Ali et al., 2017). Thus, it become unfair since the compensation amount does not coincide with the claimant situation.

Thus, this project aims to develop a mobile application, which can calculate the right total amount of compensation. This calculation adopts the Ogden Table as a model to suggest an improved method for the calculation of personal injury claims.

\section{LITERATURE REVIEW}

\section{Odgen Table Approach}

Ogden tables is a set of statistical tables with information to use by the court in the United Kingdom. The purpose is to make sure that the compensation is easier to calculate future losses in personal injury and 
fatal accident cases (Levene, 2017). This method considered all aspect such as age, sex, whether disabled before the accident, whether not disabled, level of educational attainment, whether in work at the time of the accident, whether in work at the date of the schedule, retirement age had she or he not been injured, retirement age now, pre-accident earning capacity and post-accident earning capacity (Levene, 2017). This consideration is very applicable since all the consideration is fair to all claimants. Thus, the compensation never overestimates or underestimate. This method is strengthened its usefulness by the Mohamad et al(2012)and stated that this Ogden table can be a model to develop an effective method for the calculation the compensation.

Below shows the calculation, how to make a claim using this method.

$c 1, c 2=$ pre-injury earning amount

Then, get the value of $\mathrm{d} 1$ and $\mathrm{d} 2$

$a m \times b m \times c 1=d 1$; male

af $\mathrm{x}$ bf $\mathrm{xc} 2=\mathrm{d} 2$; female

$f 1, f 2=$ post-injury earning amount

Then, get the value of $\mathrm{g} 1$ and $\mathrm{g} 2$

am $\times$ em $\times f 1=g 1$;male

af $\times$ ef $\times f 2=g 2$;female

Then, find total

$$
\begin{gathered}
d 1-g 1=h m ; \text { male } \\
d 2-g 2=h f ; \text { female }
\end{gathered}
$$

Calculation of total claim value involve am stand for multiplier valueof loss of earning to pension age 65 males with basis of a $2 \frac{1}{2} \%$ rateof return in from Ogden Table (we assume as Table 1 or known as Table 9 in Ogden Table). Meanwhile, afis multiplier value for loss of earning to pension age 60 females with basis of a $2 \frac{1}{2} \%$ rate of return in from Ogden Table (we assume as Table 2 or known asTable 8 in Ogden Table).

The user inserts the details of their educational level,capability before the accident and their working status before theaccident, 
the system will identify the value $\mathbf{b m}$. bmis themultiplier value of loss of earning to pension age 65 males inOgden Table by considering able to work before accident with their educational level and working status (we let as Table 3 or known as Table A in Ogden Table) while for disabled to work before accident (we let as Table 5 or known as Table B in OgdenTable).

For gender female, we used the notation bf as the multiplier value of loss of earning to pension age 60 females in Ogden Table by considering able to work before accident with theireducational level and working status (we let as Table 4 or known as Table $\mathrm{C}$ in Ogden Table) while for disabled to work before accident (we let as Table 6 or known as Table D in Ogden Table).

After that, the user will insert their amount the received in pre-injury (before accident), represent by $\mathbf{c 1}$ for male or $\mathbf{c 2}$ for female. The first process occurs here as we want to calculate the Damages for loss of earning I:

i. Damages for loss of earning I for male, $\mathbf{d 1} \mathbf{1}=\mathbf{a m} \mathbf{x} \mathbf{b m} \mathbf{x} \mathbf{c 1}$

ii. Damages for loss of earning I for female, $\mathbf{d} 2=\mathbf{a f} \mathbf{x} \mathbf{b f} \mathbf{x} \mathbf{c 2}$

Next step is the user will key in their working status and capability of work after the accident (post-injury). For gender male, the notation is emand female will be noted as ef. Same as before, male will refer to Table 3 or Table 5 while for female will use Table 4 or Table 6 . Then, the user will insert post-injury amount given by the court and represent by $\mathbf{f 1}$ (male) and $\mathbf{f} \mathbf{2}$ (female). Second process occur by calculating the Damages for loss of earning II where:

i. Damages for loss of earning II for male, $\mathbf{g 1}=\mathbf{a m} \mathbf{x} \mathbf{e m} \mathbf{x} \mathbf{f 1}$

ii. Damages for loss of earning II for female, $\mathbf{g} \mathbf{2}=\mathbf{a f} \mathbf{x}$ ef $\mathbf{x} \mathbf{f} 2$

Lastly is third process, award for loss of earning or display output as Total Claim. It also categorized by gender.

i. Total claim for male, $\mathbf{h m}=\mathbf{d 1} \mathbf{- g} \mathbf{1}$

ii. Total claim for female, $\mathbf{h f}=\mathbf{d} \mathbf{2}-\mathbf{g} \mathbf{2}$

\section{METHODOLOGY}

Methodology that used in these applications is waterfall model as in figure 1.Waterfall model is a traditional model of developing software, 
and there are several stages to develop the software in this model, such as requirement analysis, design, development, testing and documentation(Chandra, 2015)

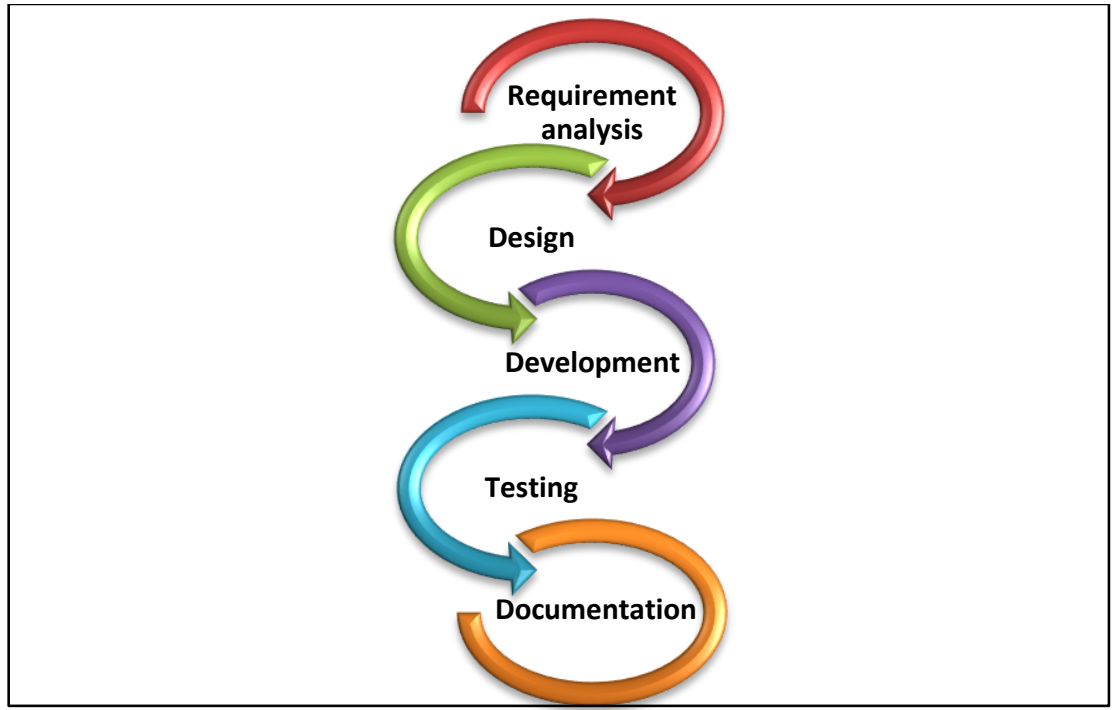

Figure 1 Waterfall Model

i. Requirement Analysis: Finding information about personal Injury claim and study all the requirements needed in the project. Searching for all the information that are related to the topic and understand the users' requirements.

ii. Design: Creating a sitemap and a wireframe to design the interface of personal Injury Claim Mobile Application.

iii. Development: Using Android studio,MySQLi, PHP code in developmentand combine the entire interface.

iv. Testing: Usability testinghas been conducted for verifying the mobile application performance and function are in good terms according to the expectation of the mobile application specification.

v. Documentation: Document all the activities as a final report.

\section{Personal Injury Claim Mobile Application Interface and Functions}

The main pages that are involve for personal injury claim applications is login, add claim, history, home, profile, report and users page. Figure 
2 below shows the navigation hierarchy for the personal injury claim application.

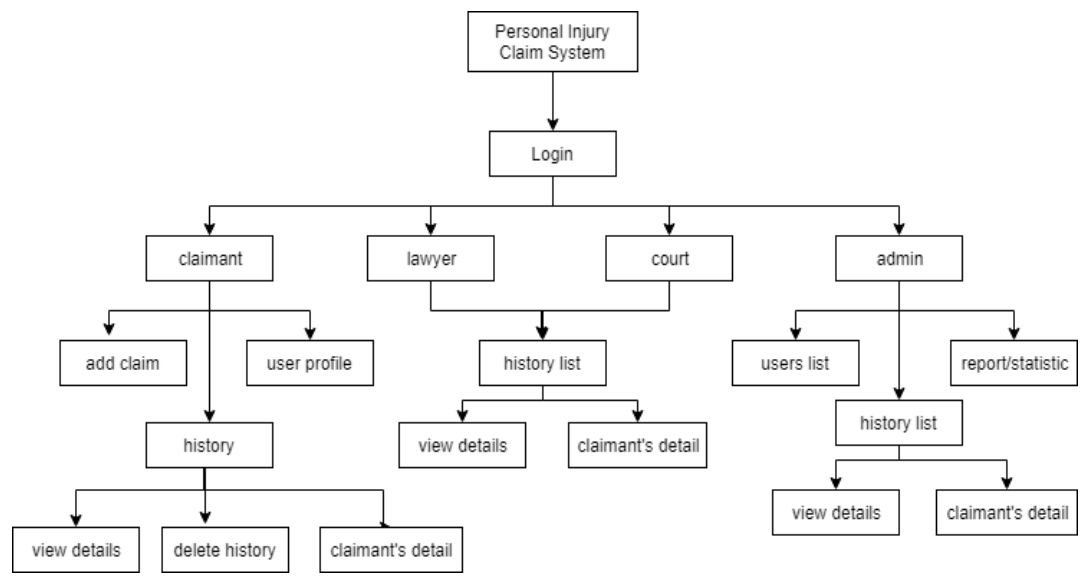

Figure 2: Hierarchy of the Personal Injury Claim Application

\section{i. Login Page}

Login page is an interface that are used to login into the application. Figure 3 shows the login page. When the users open the application, it will begin by showing the login page. Forthe users to login into the applications. Users need to input the username and password.

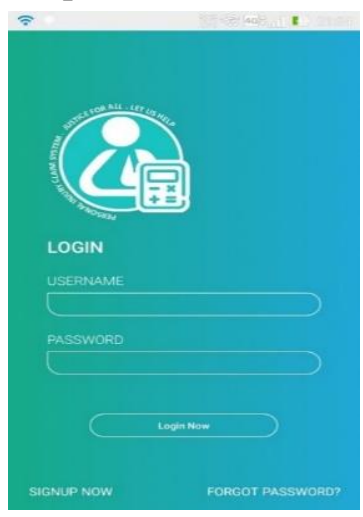

Figure 3: Login page 
Figure 4 shows the register pop up in the login page. There are four type of account: claimant, court, lawyer and admin. For the claimant account,a user has a few steps to follow in order to $\log$ in, which isa user need to Sign up.

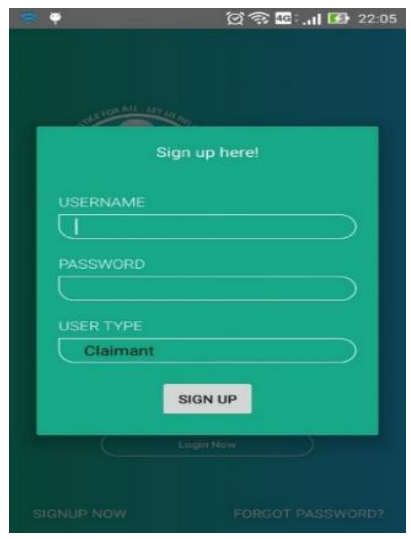

Figure Error! No text of specified style in document.: Register Pop Up

Users need to input username, password and user type in register form. Then, user need to choose at the user type text view by clicking on it and the pop-up will appear. For the admin, it is having default account in it which the password are admin and username are admin in order to $\log$ in into the application.

\section{ii. Interface for claimant}

Claimant is a user that are used this application to calculate the claim. Figure 5 below shows home page for claimant. After the claimant successfully login into the application. The application will redirect from the login page into home page. This page will explain to the user how to use this application. 


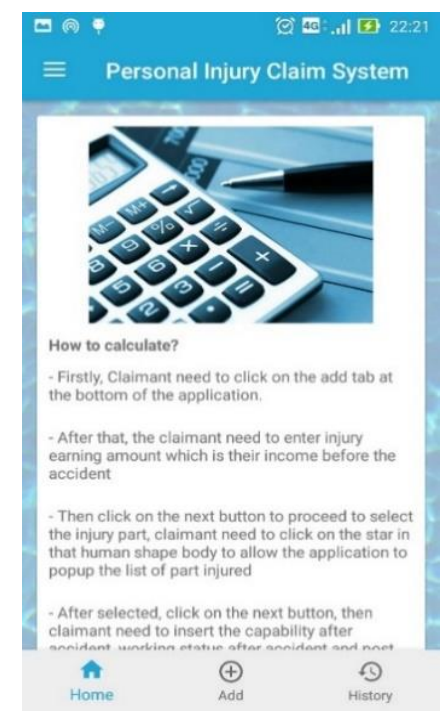

Figure 5: Home Page for Claimant

Figure 6 shows the interfaces for calculating the claim. In order for the claimant to calculate the total claim, the claimant needs to click on the tab below the applications named "Add" at the figure 6 below.

Then, the claimant needs to insert pre-injury earning amount, which is the salary of the claimant before accident, their injury part, capability and working status after accident. The claimant also needs to insert post injury earning amount given by the court.Then, finally submit their claim.

Example of claim calculation:

A 54-year-old male worker. After the accident, he became paralyzed.

Damages for loss of earning I : am $x \boldsymbol{b m} x \boldsymbol{c l}=d 1$

Damages for loss of earning I: $9.33 \times 0.79 \times 5,000=36,853.5$

$\boldsymbol{f 1}$ - the post-injury amount given by the court (after accident), which is consider about capability, working status after accidentand the cost of injured part in our body such as head, upper limb, lower limb or back bone. 
Damages for loss of earning II : am $x$ em $x \boldsymbol{f l}=\boldsymbol{g} 1$

Damages for loss of earning II : $9.33 \times 0.54 \times 20000=100,764$

Then, find total claim:

Award for loss of earnings: $\mathbf{d l} \mathbf{- g} \mathbf{l}=\mathbf{h m}$

The total claim; $100,764-36,853.5=63910.5$

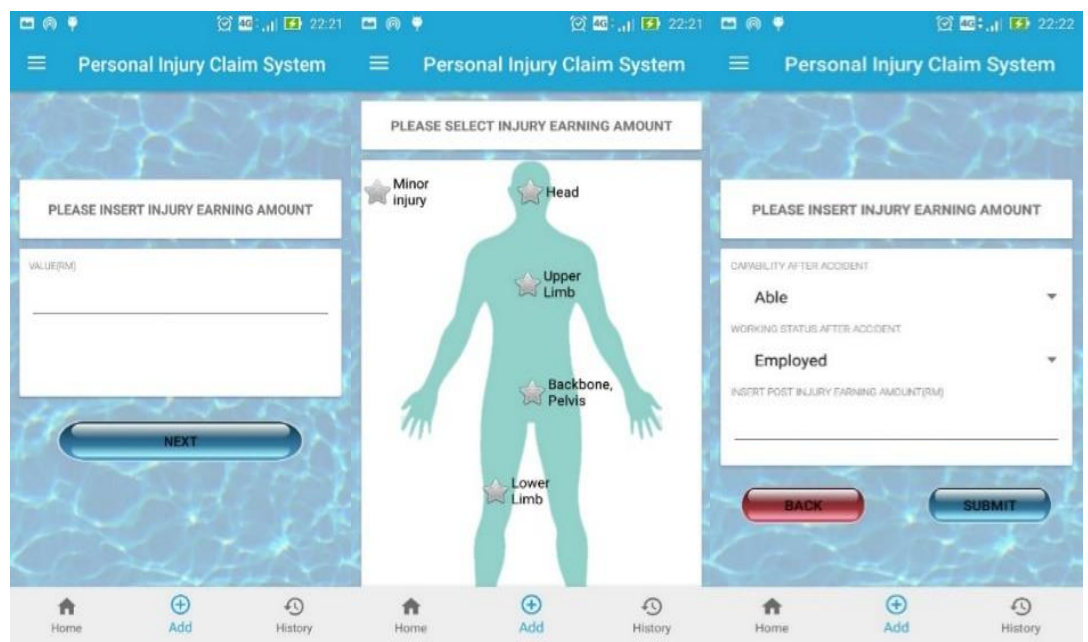

Figure 6: Interfaces for Calculate Claim

Figure 7 shows the interfaces of claimant history. Information about claim and claimant will be recorded in the history page. In this page, claimant able to view and delete the details of the history. 


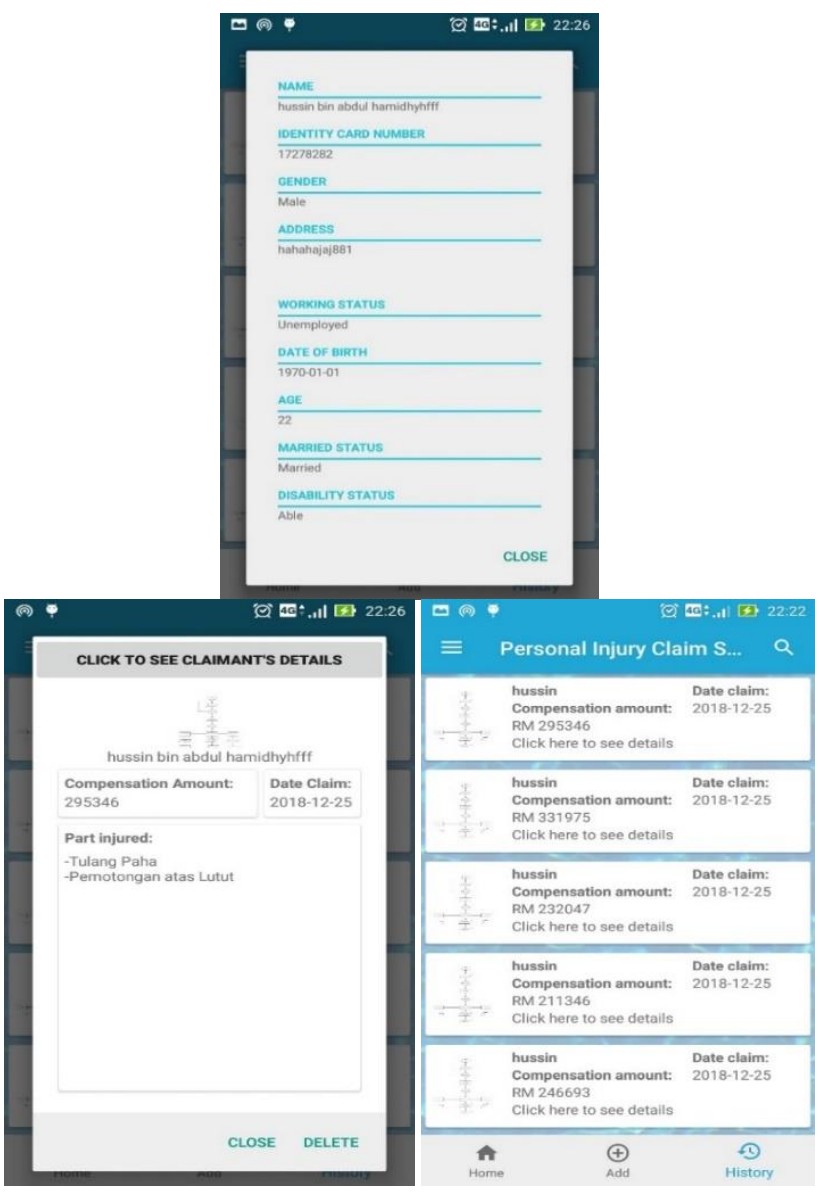

Figure 7: Interfaces of Claimant's History 


\section{RESULT AND ANALYSIS}

Usability test were carried out to get the respond and to collect data from respondents about personal injury claim system.Usability testing is a testing that are done to verify the application whether it is meet the client requirement or not. It is tested by the real users and are given a survey.The participants were given a mobile phone to use and navigate through Mobile personal injury claim system, and then they were asked to answer a questionnaire. Table 1 shows the measurement criteria used in questionnaire for usability test:

Table 1: Measurement Criteria

\begin{tabular}{|c|c|}
\hline Rank & Value \\
\hline Strongly Disagree & 1 \\
\hline Disagree & 2 \\
\hline Neutral & 3 \\
\hline Agree & 4 \\
\hline Strongly Agree & 5 \\
\hline
\end{tabular}

The measurement criteria have a ranking from 1 to 5 , where 5 values the highest with strongly agree and 1 value the lowest with strongly disagree.Table 2 shows the score of percentage gathered from usability test.

Table 2: Percentage score of Usability Test

\begin{tabular}{|l|l|l|l|l|l|}
\hline \multicolumn{1}{|c|}{ Description } & 1 & 2 & 3 & 4 & 5 \\
\hline $\begin{array}{l}\text { 1. Provides an interface which } \\
\text { helps to navigate better }\end{array}$ & 0 & 0 & $6.6 \%$ & $46.7 \%$ & $46.7 \%$ \\
\hline $\begin{array}{l}\text { 2. Provides an interface with } \\
\text { pleasant colors and suitable } \\
\text { font size and type }\end{array}$ & 0 & 0 & $6.7 \%$ & $60 \%$ & $33.3 \%$ \\
\hline $\begin{array}{l}\text { 3. Provides common buttons } \\
\text { for functions }\end{array}$ & 0 & 0 & $6.7 \%$ & $40 \%$ & $53.3 \%$ \\
\hline $\begin{array}{l}\text { 4. Apps can be accessed } \\
\text { anywhere and anytime }\end{array}$ & 0 & 0 & $6.7 \%$ & $66.7 \%$ & $26.7 \%$ \\
\hline 5. Helps in calculate the claim & 0 & 0 & $6.7 \%$ & $60 \%$ & $33.3 \%$ \\
\hline $\begin{array}{l}\text { 6 Helps reducing time taken in } \\
\text { calculate the claim }\end{array}$ & 0 & 0 & $6.6 \%$ & $66.7 \%$ & $26.7 \%$ \\
\hline 7. User Overall Satisfaction & 0 & 0 & $6.6 \%$ & $46.7 \%$ & $46.7 \%$ \\
\hline
\end{tabular}


Based on table 2, the result show that most of the respondent agree and strongly agree that Personal Injury Claim Application provides an interface which helps to navigate better which is both is $46.7 \%$.That is because the interface that have been built are user friendly and responsive. $60 \%$ of the respondent are strongly agreed that this application provided an interface with pleasant colors and suitable font size and type.Most of the respondents also strongly agree that Personal Injury Claim Application provides common buttons for functions which is $53.3 \%$. The respondent also agree that Personal Injury Claim application can be accessed anywhere and anytime which is $66.7 \%$. Meanwhile, $60 \%$ of the respondent also agreed that this application helps in calculating the claim. After the application has developed, users only need less than a minute to calculate the claim. As an overall, table 2 show that $46.7 \%$ of respondent are agreed and strongly agreed that this application meet their satisfaction with interface, usability and performance.

In a conclusion, the objectives for this application design have been achieved since most of the respondents gave a good response and it was found usable by them.

\section{CONCLUSION AND RECOMMENDATION}

Based on results that have been discussed in the previous chapter, it can be conclude that a Personal Injury Claim application provide much better platform for user to make a claim.

The contribution made by this application is to help the claimant to calculate the claim quickly. So, the claimant does not have to use the old system which takes a lot of time to calculate. In addition, the application uses the Ogden's table to calculate the claim, while the method is established in the UK.

In Malaysia, they are still using the Multiplier-Multiplicand approach, which is not fair given that their claims only take up to 54 years of age that does not match the Malaysian retirement age of around 60. So, Ogden method is introduced to overcome this problem, this method is very reliable and can provide anaccurate claim result. 
For future works, some injuries can also be improved by adding more injured parts in the application. So that the claimant can have various injuries to choose to make a claim calculation. In addition, the application can be improved by made a contact us function, so that the users of the application such as claimant, court and lawyer can suggest, or feedback related to the application.

\section{REFERENCES}

Mohamad, M., Hashim, H., \& Khalid, H. (2012). The Traditional Multiplier-Multiplicand Approach. International Conference on Economics Business and Marketing Management, 29, 325-329.

Ali, N. A., Syaeda, S., Saleh, M., Husna, N., Ruslawati, N., Mustapa, N., \& Yahya, M. A. (2017). The Personal Injury Claims

Calculator ( PICC ) System, 7(11), 1361-1371. https://doi.org/10.6007/IJARBSS/v7-i11/3575

Levene, S. (2017). Calculating with Ogden _ Counsel. Retrieved from https://www.counselmagazine.co.uk/articles/calculating-ogden

Chandra, V. (2015). Comparison between Various Software Development Methodologies. International Journal of Computer Applications, 131(9), 7-10. Retrieved from http://www.ijcaonline.org/research/volume131/number9/chandra2015-ijca-907294.pdf

Massita, M., Haslifah, H. \& Halim, K. (2012). The Traditional Multiplier-Multiplicand Approach, International Conference on Economic, Business and Marketing Management IPEDR, 29. Retrieved from http://www.ipedr.com/vol29/59CEBMM2012-R10013.pdf.

Lim, H. S. (1995). Assessment of Damages in Personal Injury and Fatal

Accident Claims: Principles and Practice. Perpustakaan Negara Malaysia, Kuala Lumpur: Marsden Law Book Sdn. Bhd. 